\title{
Discovery and Characterization of a High-Affinity Small Peptide Ligand, H1, Targeting FGFR2IIIc for Skin Wound Healing
}

\author{
Ying Zhao Qiang Wang Yuan Jin Yadan Li Changjun Nie Peipei Huang \\ Zhixin Li Bihui Zhang Zijian Su An Hong Xiaojia Chen
}

Institute of Biomedicine \& Department of Cell Biology, Jinan University, National Engineering Research Center of Genetic Medicine, Guangdong Provincial Key Laboratory of Bioengineering Medicine, Guangzhou, China

\section{Key Words}

Small peptide $•$ Skin wound healing $•$ FGFR2IIIc-targeting $\bullet$ High affinity $\bullet$ Phage display

\begin{abstract}
Background/Aims: How to aid recovery from severe skin injuries, such as burns, chronic or radiation ulcers, and trauma, is a critical clinical problem. Current treatment methods remain limited, and the discovery of ideal wound-healing therapeutics has been a focus of research. Functional recombinant proteins such as basic fibroblast growth factor (bFGF) and epidermal growth factor (EGF) have been developed for skin repair, however, some disadvantages in their use remain. This study reports the discovery of a novel small peptide targeting fibroblast growth factor receptor 2 IIIc (FGFR2IIIc) as a potential candidate for skin wound healing. Methods: A phage-displayed peptide library was used for biopanning FGFR2IIIc-targeting small peptides. The selected small peptides binding to FGFR2IIIc were qualitatively evaluated by an enzymelinked immunosorbent assay. Their biological function was detected by a cell proliferation assay. Among them, an optimized small peptide named $\mathrm{H} 1$ was selected for further study. The affinity of the $\mathrm{H} 1$ peptide and FGFR2IIIc was determined by an isothermal titration calorimetry device. The ability of the $\mathrm{H} 1$ peptide to promote skin wound repair was investigated using an endothelial cell tube formation assay and wound healing scratch assay in vitro. Subsequently, the $\mathrm{H} 1$ peptide was assessed using a rat skin full-thickness wound model and chorioallantoic membrane (CAM) assays in vivo. To explore its molecular mechanisms, RNA-Seq, quantitative real-time PCR, and western blot assays were performed. Computer molecular simulations were also conducted to analyze the binding model. Results: We identified a novel FGFR2IIIctargeting small peptide, called $\mathrm{H} 1$, with 7 amino acid residues using phage display. $\mathrm{H} 1$ had high binding affinity with FGFR2IIIc. The $\mathrm{H} 1$ peptide promoted the proliferation and motility of fibroblasts and vascular endothelial cells in vitro. In addition, the $\mathrm{H} 1$ peptide enhanced Y. Zhao, and Q. Wang contributed equally to this work and should be regarded as joint first authors.


angiogenesis in the chick chorioallantoic membrane and accelerated wound healing in a rat full-thickness wound model in vivo. The $\mathrm{H} 1$ peptide activated both the PI3K-AKT and MAPKERK1/2 pathways and simultaneously increased the secretion of vascular endothelial growth factor. Computer analysis demonstrated that the model of $\mathrm{H} 1$ peptide binding to FGFR2IIIc was similar to that of FGF2 and FGFR2IIIc. Conclusion: The H1 peptide has a high affinity for FGFR2IIIc and shows potential as a wound healing agent. As a substitute for bFGF, it could be developed into a novel therapeutic candidate for skin wound repair in the future.

(C) 2018 The Author(s)

Published by S. Karger AG, Basel

\section{Introduction}

The skin, including the epidermis (surface layer) and dermis (deeper layer), is the largest barrier between the human body and the external environment. When this barrier is broken, an orchestrated cascade of biochemical events is set in motion to repair the damage $[1,2]$. The classic model of wound healing involves three sequential phases: inflammation, proliferation, and remodeling $[3,4]$. This process requires the collaboration of a variety of tissues and cell types, including inflammatory cells, fibroblasts, keratinocytes, endothelial cells, and macrophages $[5,6]$. These cells are tightly regulated by cytokines, growth factors, and extracellular matrix molecules [7-9]. Although recombinant growth factors and cytokines have been clinically applied in treating skin damage, disadvantages in their use include their easy degradation and instability in vitro $[10,11]$, and the highest clinical cure rate remains at $50-60 \%$ [12]. Therefore, it is necessary to identify novel biological products with low cost and easy storage.

The fibroblast growth factor receptor (FGFR)family plays an important role in organ development and consists of 4 members (FGFR1, FGFR2, FGFR3 and FGFR4). In addition, alternate mRNA splicing generates the " $b$ " and "c"variants of FGFR 1, 2, and $3[13,14]$. FGFR2 [15] is a receptor for FGF which is important in embryonic development and tissue repair, particularly of bone and blood vessels [16-18]. FGFR2-associated signaling pathways are activated by receptor binding with its ligands [19]. Its intracelluar tyrosine kinase domains are dimerized and phosphorylated to initiate a cascade of intracellular signals that mediate cell division, growth, and differentiation [18, 20-22]. Basic fibroblast growth factor (bFGF), also named FGF2, plays an important role in wound healing [23, 24]. Our institute successfully developed the recombinant bFGF for the treatment of burns, scalds, and chronic ulcers 20 years ago. However, recombinant bFGF has a large molecular weight and a high production cost. In clinical applications, there is also the low accumulation of bFGF at on therapeutic sites, an undesired effect. In addition to bFGF, other recombinant growth factors and cytokines show similar effects.

Compared with recombinant proteins, small peptides have many characteristics such as small molecular weight and low production cost that enable them to overcome the current high cost of producing recombinant proteins. In the present study, using phage display, we obtained an FGFR2 IIIc-targeting small peptide, H1, which had a significant therapeutic effect on the healing of skin wounds.

\section{Materials and Methods}

\section{Cell lines and cultures}

Human umbilical vein endothelial cells (HUVECs), BALB/c 3T3 cells, and FGFR2IIIc-overexpressing HEK293 cells were maintained in our laboratory. All cells were cultured in high-glucose Dulbecco' s modified Eagle' s medium ( DMEM) supplemented with $10 \%$ fetal bovine serum (FBS) at $37^{\circ} \mathrm{C}$ in a humidified incubator under $5 \% \mathrm{CO}_{2}$. The culture medium was changed every $2-3$ days. 


\section{Cellular Physiology Cell Physiol Biochem 2018;49:1074-1089 \begin{tabular}{l|l|l} 
and Biochemistry Published onlıne: 6 September, 2018 & (c) 2018 The Author(s). Published by S. Karger AG, Basel \\
ww.karger.com/cpb
\end{tabular} \\ Zhao et al.: Discovery of H1 Peptide For Skin Wound Healing}

Animals

Male Sprague-Dawley rats (weighing 200-220 g) were purchased from Hua Fukang Biological Polytron Technologies Inc. (Beijing, China) and housed in temperature-controlled facilities at the Laboratory Animal Center of Jinan University. All animals were SPF class and all surgeries were performed under sodium pentobarbital anesthesia. Ultimately, all animals were euthanized.

\section{Phage library biopanning}

A Ph.D.-7 library (New England BioLabs, Ipswich, MA), displaying random 7-mer peptide sequences constructed in the M13 phage vector, was used for biopanning. Recombinant FGFR2IIIc extracellular domain proteins (Sino Biological Inc. Beijing, China) were the target for screening. First, a 35-mm plate was coated with $1 \mathrm{~mL}$ of $0.1 \mathrm{M} \mathrm{NaHCO}_{3}(\mathrm{pH} 8.6$ ) containing $10 \mu \mathrm{g} / \mathrm{mL}$ of the target and incubated overnight at $4^{\circ} \mathrm{C}$ with gentle agitation in a humidified container. Second, $1 \mathrm{~mL}$ of the Ph.D.-7 library containing a total of $2.0 \times 10^{11}$ clones was pipetted onto the coated plate and rocked gently for 10-60 min at room temperature. Third, unbound phage was removed by washing with TBST (TBS $+0.1 \%$ [v/v] Tween-20), and specifically bound phage was eluted with $1 \mathrm{~mL}$ of an appropriate elution buffer $(0.2 \mathrm{M}$ glycine- $\mathrm{HCl}$ [pH 2.2], $1 \mathrm{mg} / \mathrm{mL}$ BSA) and rocked gently for no more than 10-20 min. Next, the eluted phages were neutralized with $150 \mu \mathrm{L}$ of $1 \mathrm{M}$ Tris-HCl, pH 9.1. Finally, the recovered phages were titered and amplified in Escherichia. coli ER2738 culture. The amplified phages were used as input for the next round of biopanning as described previously. During the 3-screen process, the concentration of target proteins coated on the plate was 10, 5 and $2.5 \mu \mathrm{g}$, respectively. However, the amount of phage input remained unchanged. After 3 rounds, individual clones were characterized by DNA sequencing and an enzyme-linked immunosorbent assay (ELISA).

\section{Phage ELISA binding assay with direct target coating}

At first, a 96-well ELISA plate was coated with $100 \mu \mathrm{L}$ of $10 \mu \mathrm{g} / \mathrm{mL}$ of target in $0.1 \mathrm{M} \mathrm{NaHCO3(pH} \mathrm{8.6)}$ and incubated overnight at $4^{\circ} \mathrm{C}$ in an airtight humidified box. Second, after washing, each well was filled completely with blocking buffer $\left(0.1 \mathrm{M} \mathrm{NaHCO}_{3}, \mathrm{pH} 8.6,5 \mathrm{mg} / \mathrm{mL} \mathrm{BSA}\right)$ and incubated for $1-2 \mathrm{~h}$ at $4^{\circ} \mathrm{C}$. Third, individual phage clones $\left(1.0 \times 10^{9}\right.$ plague-forming units $)$ were added to the target-coated plate and incubated at room temperature for 1-2 $\mathrm{h}$ with agitation. Next, the plate was washed with TBST and incubated with a horseradish peroxidase (HRP)-conjugated anti-M13 monoclonal antibody (Cat \#DMABT-Z60493, Creative Diagnostics, New York, NY) at room temperature for $1 \mathrm{~h}$ with agitation. The plate was washed with TBST and incubated with the HRP substrate solution for $10 \mathrm{~min}$ at room temperature with gentle agitation. Finally, the reaction was terminated by adding $2 \mathrm{M} \mathrm{H}_{2} \mathrm{SO}_{4}$, and the plate was read using a microplate reader set at $450 \mathrm{~nm}$. The selected phage clones were analyzed further using DNA sequencing with the reverse primer 5'-HOCCC TCA TAG TTA GCG TAA CG-3'. In addition, the phage-displayed peptide sequences were translated using Primer Premier 5.0 software.

\section{Peptide synthesis}

Peptides H1, H2, H3, and H4 were synthesized by Bootech BioScience \& Technology Co., Ltd. (Shanghai, China) and analyzed by high-performance liquid chromatography (HPLC) and mass spectrometry to confirm their purity was $\geq 98$.

\section{Cell proliferation assay}

The cells $\left(3.0 \times 10^{3}\right.$ cells/well, $\left.100 \mu \mathrm{L}\right)$ were plated in a 96-well plate. After an overnight incubation, the cells adhered to the plates. The complete medium was then replaced withfresh medium supplemented with $0.5 \%$ FBS, and the cells were starved for $12 \mathrm{~h}$. Next, the $\mathrm{H} 1$ peptide was dissolved in DMEM at different concentrations $(0,0.00128,0.0064,0.032,0.16,0.8,4$ and $20 \mu \mathrm{M}, 100 \mu \mathrm{L})$ and added to the wells and incubated for $48 \mathrm{~h}$. An identical volume of DMEM was used as a blank control. Finally, a Cell Counting Kit8 (CCK8, Dojindo, Kumamoto, Japan) was added to the wells for a further $2 \mathrm{~h}$ of incubation at $37^{\circ} \mathrm{C}$. The absorbance of each well was measured using an ELISA microplate reader at $450 \mathrm{~nm}$. Experiments were conducted independently in triplicate. 


\section{Cellular Physiology Cell Physiol Biochem 2018;49:1074-1089 and Biochemistry Published online: 6 September, 2018 www.karger.com/cpb 10201 The Aublished by S. Karger AG, Basel \\ Zhao et al.: Discovery of H1 Peptide For Skin Wound Healing}

sterile water. These samples were thoroughly degassed and then centrifuged to remove precipitates. The binding of both was measured by ITC using a MicroCal Omega ITC200 system (MicroCal, Northampton, MA) at $25^{\circ} \mathrm{C}$ using $0.1 \mathrm{mM} \mathrm{H} 1$ peptide in the sample cell and $0.001 \mathrm{mM}$ FGFR protein in the injecting syringe. Throughout the experiment, 19 drops were injected into the sample cell, and each drop had a volume of $2 \mu \mathrm{L}$. The interval between each drop was $5 \mathrm{~min}$. ITC data were analyzed with a single-site binding model using Origin 7.0 software (OriginLab Corp., Northampton, MA).

\section{Fibroblast wound scratch assay}

BALB/c 3T3 cells $\left(3.0 \times 10^{4}\right)$ were seeded in a 6-well plate and incubated at $37^{\circ} \mathrm{C}$ in $5 \% \mathrm{CO}_{2}$ for $24 \mathrm{~h}$ to create confluent monolayers. Next, after $12 \mathrm{~h}$ of serum starvation (DMEM supplemented with $0.5 \%$ FBS), the cell monolayer was subjected to a mechanical scratch wound using a sterile pipette tip and washed twice with phosphate-buffered saline to remove floating cells. Then, the cells were incubated with the H1 peptide $(20 \mu \mathrm{M})$ for $24 \mathrm{~h}$. During the experiment, bFGF $(30 \mathrm{ng} / \mathrm{mL})$ was used as a positive control. After 24 $\mathrm{h}$, the images were obtained using a microscope, and cell migration activity was quantified using the ImageJ software (National Institutes of Health, Bethesda, MD). The migration ratio was calculated as follows: (the width of the original scratch - the width of the actual scratch) / (the width of the original scratch) $\times 100$. Experiments were conducted independently in triplicate.

\section{Endothelial cell tube formation assay}

Matrigel (Cat \#356230, BD Biosciences, Bedford, MA) was dissolved at $4^{\circ} \mathrm{C}$ overnight. In advance, 96well plates and pipette tips were precooled. Matrigel matrix $(80 \mu \mathrm{L})$ was added to each well of the precooled 96-well plate and incubated for $30 \mathrm{~min}$ at $37^{\circ} \mathrm{C}$. HUVECs $\left(2.0 \times 10^{4}\right)$ were seeded into the 96 -well plate and cultured in serum-free medium, including the $\mathrm{H} 1$ peptide $(20 \mu \mathrm{M})$. During the experiment, bFGF $\left(30 \mathrm{ng} / \mathrm{mL}\right.$ ) was used as a positive control. After $12 \mathrm{~h}$ of incubation at $37^{\circ} \mathrm{C}$, HUVEC tube formation was photographed under a light microscope and quantified using ImageJ software. Experiments were conducted independently in triplicate.

\section{Chorioallantoic membrane assay}

Angiogenesis was assayed using a chorioallantoic membrane assay. Seventy fertilized chicken eggs were incubated at $37^{\circ} \mathrm{C}$ in a $60-70 \%$ humidified atmosphere. On day 6 , the $\mathrm{H} 1$ peptide, dissolved in normal saline at different concentrations $(1,10,100$ and $1000 \mu \mathrm{M}, 100 \mu \mathrm{L})$, was added to the center of the chorioallantoic membrane. bFGF (100 ng/mL) and normal saline were used as positive and negative controls, respectively. There were 10 eggs in each group. After 2 days of incubation, chorioallantoic membranes were photographed under a stereomicroscope. Angiogenesis was quantified by counting the number of blood vessel branches using Image-Pro Plus v 6.0 software (Media Cybernetics, Rockville, MD).

\section{Rat skin full-thickness wound model}

Male Sprague-Dawley rats, weighting 200-220 g, were injected intraperitoneally with $40 \mathrm{mg} / \mathrm{kg}$ pentobarbital sodium dissolved in normal saline. Dorsal hair was removed using an electric clipper. Six-6 mm full-thickness excisional wounds were created on the back of each rat using 9-mm diameter operating scissors and sterilized with $75 \%$ alcohol. After wounding, the rats were housed separately until the end of the experiment. Wounded rats were divided randomly into 3 groups ( 3 rats per group). The rats were treated with the $\mathrm{H} 1$ peptide $(10 \mu \mathrm{g} / \mathrm{mL}, 20 \mu \mathrm{L})$ applied topically to the wound site twice daily. bFGF $(100 \mu \mathrm{g} / \mathrm{mL})$ and normal saline were used as positive and negative controls, respectively. The wound was photographed with a digital camera once every 2 days. One week later, all of the rats were euthanized, and the injured area was analyzed further.

\section{Histology and immunohistochemistry}

Skin tissues were obtained from sacrificed rats and processed into paraffin sections (5-mm thick) for further investigation. Tissue sections were stained with hematoxylin and eosin (HE) for morphological assessment. Immunohistochemical staining for proliferating cell nuclear antigen (PCNA), CD31, CK19, and vascular endothelial growth factor (VEGF) was performed with specific antibodies for each protein (Santa Cruz Biotech, Santa Cruz, CA). First, sections that were dewaxed and hydrated were blocked with $3 \% \mathrm{H}_{2} \mathrm{O}_{2}$ for $10 \mathrm{~min}$, followed by blocking with $1 \%$ BSA for $30 \mathrm{~min}$. Then, the sections were incubated with 


\section{Cellular Physiology Cell Physiol Biochem 2018:49:1074-1089 and Biochemistry $\begin{gathered}\text { DOI: 10.1159/000493287 } \\ \text { Published }\end{gathered}$

primary antibodies (at a dilution of 1:100) overnight at $4^{\circ} \mathrm{C}$. Next, sections were incubated with biotinylated secondary antibodies (at a dilution of 1:200) at room temperature for $30 \mathrm{~min}$, followed by incubation with HRP-streptavidin (at a dilution of 1:400) for 30 min. Finally, the sections were stained with DAB for 3-5 $\mathrm{min}$, followed by hematoxylin counterstaining, dehydration, and coverslipping. All samples were observed through a high-power light microscope (Nikon, Tokyo, Japan).

\section{RNA-Seq}

The sequencing libraries were constructed following the TruSeqTM RNA Sample Preparation Guide (Illumina, San Diego, CA). When library construction ended, the library preparations were sequenced on an Illumina HiSeq 2500 platform and 125-bp paired-end reads were generated. Subsequently, sequence read mapping, assembly, and annotation were conducted. During the process, raw data (raw reads) infastq format were first processed through in-house Perl scripts. In this step, clean data (clean reads) were obtained by removing reads containing an adapter, reads containing poly-N, and low-quality reads from the raw data. Simultaneously, Q20, Q30, GC-content, and sequence duplication level of the clean data were calculated. All of the downstream analyses were based on high-quality clean data. High-quality reads were mapped to a human mRNA reference sequence (hg19 2015-03-17). mRNA abundance was normalized using both reads per kilobase per million reads and edgeR [25] package methods. Genes with $>10$ mapped reads were considered to be quantified genes. Meanwhile, the screening threshold in the differential expression analysis of transcripts was set to $\mid \log 2$ (FoldChange) $\mid>1$ and $\mathrm{P}<0.05$. That is, genes with a P-value < 0.05 were designated as differentially expressed. In the relevant literature, more detailed processes are described [26].

Gene Ontology (GO) and Kyoto Encyclopedia of Genes and Genomes (KEGG) enrichment analysis of differentially expressed transcripts

GO is divided into three aspects: molecular functions, biological processes, and cell composition. We used topGO (version 2.18.0) to analyze differentially expressed genes (DEGs) for GO enrichment, and Fisher' s, exact test was used for statistical analysis. In vivo, different genes coordinate their biological functions with one another. By pathway enrichment, the major biochemical metabolic pathways and signal transduction pathways involved in the differential expression of genes can be determined. We screened the DEGs using KEGG pathway enrichment analysis. The analysis software was KOBAS (version 3.0) [27], and the statistical test method was the hypergeometric test. $\mathrm{P}<0.05$ was defined as statistically significant.

\section{RNA extraction and quantitative real-time PCR ( $q P C R$ ) analysis}

Total RNA was extracted from HUVECs using RNAiso plus (Cat \#9108/9109, TaKaRa, Dalian, China) following the manufacturer's instructions. Total RNA $(1 \mu \mathrm{g})$ was reverse-transcribed into cDNA using a PrimeScript ${ }^{\mathrm{TM}}$ RT Reagent Kit with gDNA Eraser (Cat \#RR047A, TaKaRa). Real-time PCR was performed with SYBR ${ }^{\circledR}$ Premix Ex Taq ${ }^{\text {TM }}$ (Cat \#RR820A, TaKaRa) in a CFX96 Real-Time PCR Detection System (Bio-Rad, Hercules, CA) with the following conditions: $95^{\circ} \mathrm{C}$ for $30 \mathrm{~s}$, and 39 cycles of $95^{\circ} \mathrm{C}$ for $5 \mathrm{~s}, 55^{\circ} \mathrm{C}$ for $30 \mathrm{~s}$, and $72^{\circ} \mathrm{C}$ for $30 \mathrm{~s}$. Glyceraldehyde-3-phosphate dehydrogenase (GAPDH) was used as an internal control. Each plate had 3 repeated samples, and the reactions were performed 3 times independently. Gene expression was evaluated by the $2^{-\Delta \Delta c t}$ method [28]. The primer sequences are listed in Supplementary Table 1 (For all supplemental material see www.karger.com/10.1159/000493287/).

\section{Western blot analysis}

The cells were lysed using RIPA lysate (Cat \#P00138, Beyotime, Shanghai, China) containing proteinase inhibitors. Protein samples of the same concentration were separated by $12 \%$ sodium dodecyl sulfatepolyacrylamide gel electrophoresis. The separated protein samples were transferred to a polyvinylidene fluoride membrane using electrophoresis. Subsequently, the membrane was blocked with $5 \%(\mathrm{w} / \mathrm{v})$ $\mathrm{BSA}$ for $1 \mathrm{~h}$ at room temperature and incubated with primary antibodies at $4^{\circ} \mathrm{C}$ overnight. The primary antibodies used in the experiments were as follows: anti-Akt antibody, anti-Phospho-Akt (Ser473) (D9E) XP® rabbit monoclonal, anti-p44/42 MAPK (Erk1/2),anti-phospho-p44/42 MAPK (Erk1/2) (Thr202/ Tyr204), and anti- $\beta$-actin (Cell Signaling Technology, Beverly, MA). The blots were washed 5 times with TBST and incubated with a secondary antibody (Cell Signaling Technology) for $1 \mathrm{~h}$ at room temperature. 


\section{Cellular Physiology Cell Physiol Biochem 2018;49:1074-1089 \begin{tabular}{l|l|l} 
and Biochemistry Published online: 6 September, 2018 & $\begin{array}{l}\text { (c) } 2018 \text { The Author(s). Published by S. Karger AG, Basel } \\
\text { ww.karger.com/cpb }\end{array}$
\end{tabular} \\ Zhao et al.: Discovery of H1 Peptide For Skin Wound Healing}

The blots were washed again 5 times with TBST and then developed using enhanced chemiluminescence (Cat \#34096, Thermo Fisher Scientific, Rockford, IL).

ELISA

HUVECs were cultured in 24-well culture plates overnight. Then, the cells were pretreated with the $\mathrm{H} 1$ peptide at a gradient concentration and incubated in a humidified incubator at $37^{\circ} \mathrm{C}$ for $24 \mathrm{~h}$. After incubation, VEGF in the medium was detected using a VEGF Human ELISA Kit (Cat \#KHG0112, Thermo Fisher Scientific) according to the manufacturer' instructions.

\section{Molecular docking calculations and molecular dynamics simulations}

Molecular docking is a computer simulation approach that attempts to predict the binding mode and affinity of a ligand to the active site of a protein [29-31]. Molecular docking of the H1 peptide on the extracellular segment of FGFR2IIIc protein was evaluated with LeDock software (http://www.lephar.com/). LeDock is based on a combination of simulated annealing and genetic algorithms. The crystal structure of the FGFR2IIIc extracellular domain was derived from the Protein Data Bank (PDB ID:1EV2). All calculations were performed on an Ubuntu Linux 16.04 platform. During the docking process, we removed the water molecules and hydrogen atoms of the crystal structure of the FGFR2IIIc extracellular domain while retaining the $\mathrm{F}$ chain as the template molecular docking chain. Later, we re-added the hydrogen atoms to ensure the protonation of the amino acid residues and corrected the irrational chemical bonds. Docking scores were calculated by the binding free energies. The optimal conformation was obtained as our further analysis object. Next, we conducted molecular dynamics simulations of 50 ns to verify the stability of the H1-FGFR2IIIc complex in ionic solvents. We used the Gromacs5.1.4 program to perform full atom molecular dynamics simulation of the complex under the CHARMM27 force field. The complex entered the 12-body periodic simulation box at $1.2 \mathrm{~nm}$ away from its boundary. First, we minimized the energy of the complex in a hypothetical vacuum. The judgment basis of energy convergence was set at $100.0 \mathrm{KJ} \mathrm{mol}^{-1} \mathrm{~nm}^{-1}$, and convergence was achieved after 4376 steps. Next, we used the SPC/E water model to fill the simulation box with solvents. To maintain the system' s electrostatic charge balance, we added $118 \mathrm{Na}$ ions and $122 \mathrm{Cl}$ ions, and eventually the ionic concentration of the solution reached $150 \mathrm{mM}$. Then, we conducted a positionconstrained pre-equilibrium simulation. In this process, we used the LINCE algorithm to constrain the chemical bonds of the complex system. The accuracy of LINCE was set to 1. The order of LINCS was set to 4 . The truncation value of the electrostatic action was set to $1.0 \mathrm{~nm}$. Simultaneously, we used the particle mesh Ewald electrostatic method to calculate the electrostatic interaction. In the process of molecular dynamics simulation, we first performed a pre-equilibrium simulation of 100 ps under the NVT ensemble and then performed a pre-equilibrium simulation of 100 ps under NPT. Finally, the finished product simulation of 50 ns was performed under NPT.

\section{Statistical analysis}

All data are shown as the mean \pm standard deviation (SD). Differences between groups were assessed using analysis of variance or t-test with Prism 5.0 software (GraphPad Software, Inc., San Diego, CA). P $<0.05$ was considered statistically significant.

\section{Results}

\section{Identification of peptides targeting FGFR2IIIc with high affinity}

A Ph.D.-7 library was used for biopanning phages targeting the extracellular domain of recombinant FGFR2IIIc protein (Fig. 1A). After 3 rounds of screening, the phage titer was enriched by approximately 93-fold compared with that of the first round (Fig. 1B). Simultaneously, during the screening process, the $\mathrm{P} / \mathrm{N}$ value was also increased by round, and it reached 342 by the third round (Fig. 1C). Table 1 also demonstrates that the FGFR2IIIctargeting phages were effectively enriched after 3 rounds of screening. This result suggested that the screening was sufficiently specific. Then, 35 phage clones were randomly selected from the third round, and the peptide-coding DNA inserts of the phage clones were sequenced. 
A

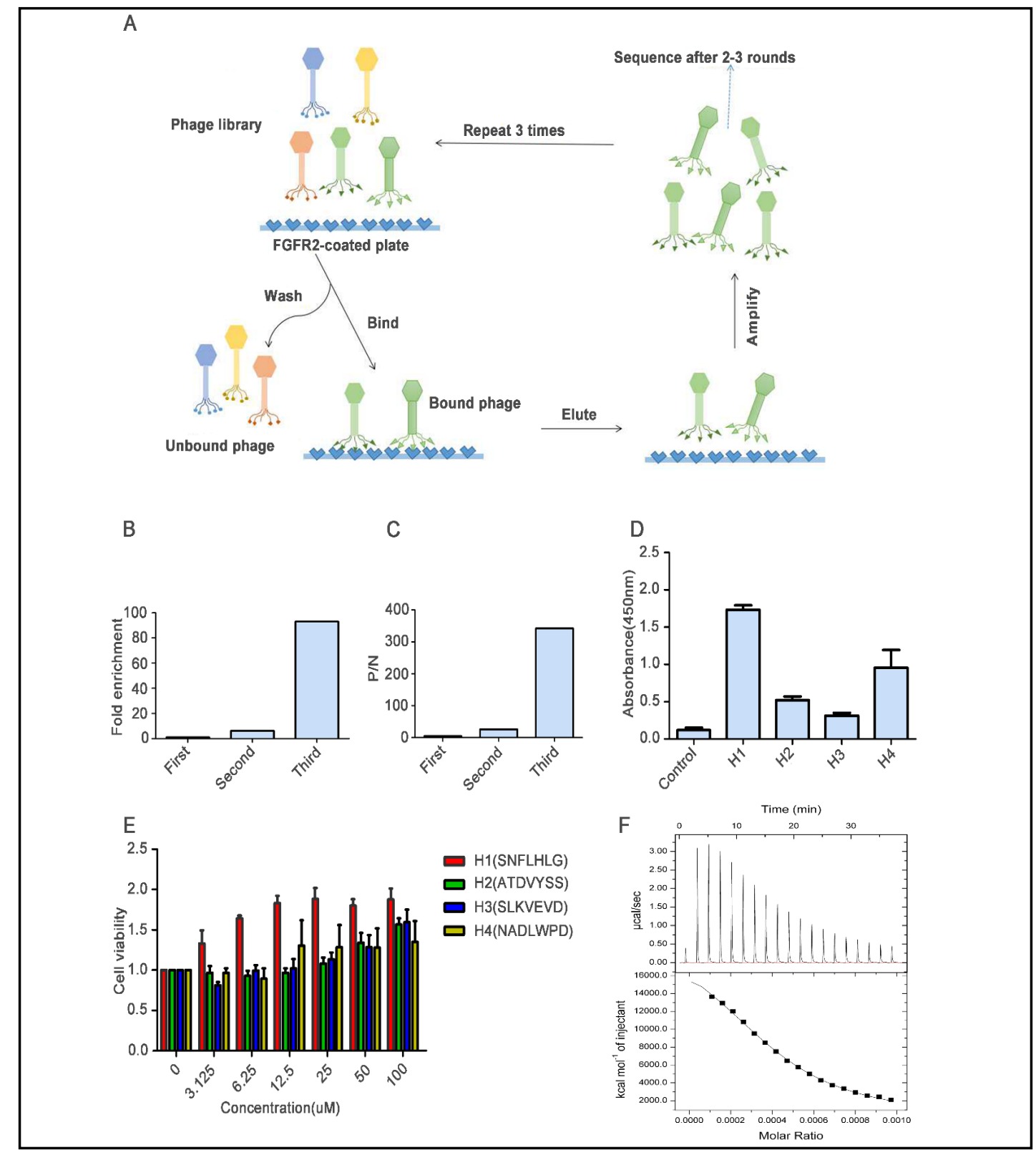

Fig. 1. Phage display screening for peptides targeting FGFR2IIIc. (A) Schematic of phage library screening. A library of phage-displayed peptides was incubated in a plate coated with the extracellular domain of recombinant FGFR2IIIc protein, unbound phages were removed by washing, and specifically bound phages were eluted. The eluted phages were then amplified and used as input for the next round of biopanning. After 3 rounds, individual clones were characterized by DNA sequencing and ELISA. (B) After each screening round, the binding efficiency of the phage pools was assessed by phage titer. Bars represent the relative fold enrichment of phage titer at each round over the titer at the first round. (C) The $\mathrm{P} / \mathrm{N}$ value represents the binding specificity of the phage pools (P: output phage; N: output phage of negative control). (D) Phage ELISA binding assay. Individual phage clones were incubated in a 96-well ELISA plate coated with the target protein FGFR2IIIc. Target-bound phages were detected with HRP-conjugated anti-phage antibodies. Bars represent the absorbance value at $450 \mathrm{~nm}$ of each phage clone. (E) Cell viability assays of FGFR2IIIcoverexpressing HEK293 cells incubated with the $\mathrm{H} 1, \mathrm{H} 2, \mathrm{H} 3$ or $\mathrm{H} 4$ peptides at a concentration gradient for $48 \mathrm{~h}$. (F) Detection of binding affinity between the H1 peptide and FGFR2IIIc by ITC analysis. The upper panel displays the thermogram (thermal power vs. time) after baseline correction, and the lower panel displays the binding isotherm. All experiments were repeated 3 times, and each error bar represents SD. 
After sequence alignment, we obtained 4 small peptides, which were named H1, H2, H3 and $\mathrm{H} 4$. The 4 peptides were synthesized, and their molecular weights were measured by mass spectrometry (Supplementary Fig. S1A-D). The relative binding affinity of the selected phage clones was determined qualitatively by ELISA. Among them, the clone displaying the sequence SNFLHLG, namely, H1, appeared to have the strongest binding ability (Fig. 1D).

Subsequently, a cell proliferation assay was performed to assess the biological function of these peptides using a CCK8 kit. The results indicated that the $\mathrm{H} 1$ peptide had the most remarkable effect of 4 peptides on cell growth (Fig. 1E). Therefore, the H1 peptide was selected for further investigation.

The previous experiments only $\mathrm{d}$ e m o n s t r a t e d qualitatively that the $\mathrm{H} 1$

Table 1. Screening of a phage library for peptides

\begin{tabular}{lcccccc}
\hline Round & $\begin{array}{c}\text { FGFR2IIIc } \\
\text { (u g) }\end{array}$ & $\begin{array}{c}\text { Input phage } \\
\text { (p.f.u) }\end{array}$ & $\begin{array}{c}\text { Output phage } \\
\text { (p.f.u) } \\
\text { P }\end{array}$ & $\begin{array}{c}\text { Output phage of negative control } \\
\text { (p.f.u) } \\
\text { N }\end{array}$ & $\begin{array}{c}\text { Recovery } \\
\text { (\%) }\end{array}$ & P/N \\
\hline 1 & 10 & $2 \times 10^{11}$ & $1.4 \times 10^{5}$ & $2.7 \times 10^{4}$ & $7 \times 10^{-5}$ & 5 \\
2 & 5 & $2 \times 10^{11}$ & $8.7 \times 10^{5}$ & $3.4 \times 10^{4}$ & $4.35 \times 10^{-4}$ & 26 \\
3 & 2.5 & $2 \times 10^{11}$ & $1.3 \times 10^{7}$ & $3.8 \times 10^{4}$ & $6.5 \times 10^{-3}$ & 342 \\
\hline
\end{tabular}

Fig. 2. Effect of the $\mathrm{H} 1$ peptide on the proliferation and motility of fibroblasts and vascular endothelial cells. (A-C) Cell viability results for $\mathrm{BALB} / \mathrm{c} \quad 3 \mathrm{~T} 3$ cells and HUVECs. The cells were incubated with the H1 peptide or bFGF at a concentration gradient. (D) Cell scratch assay to measure the migration of BALB/ c3T3 cells. The cells were scratched and treated with normal saline, bFGF (30 $\mathrm{ng} / \mathrm{mL}$ ), or the $\mathrm{H} 1$ peptide $(20 \mu \mathrm{M})$ for $24 \mathrm{~h}$. The green line denotes the margin of the gap. The repair rate of

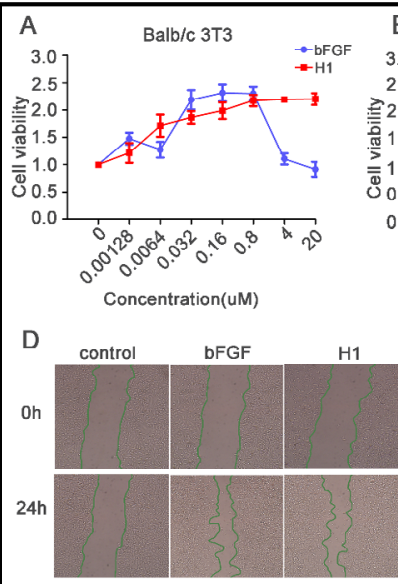

E

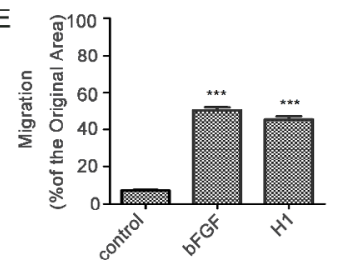

$\mathrm{H}$

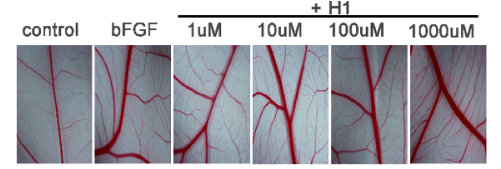

C HUVEC
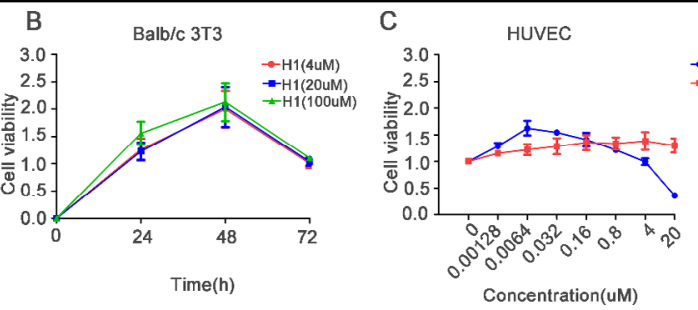

F

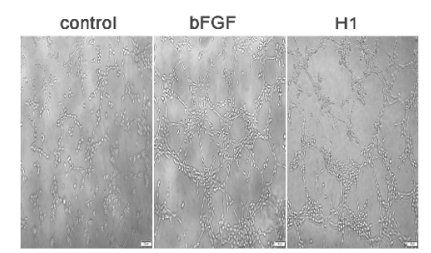

G
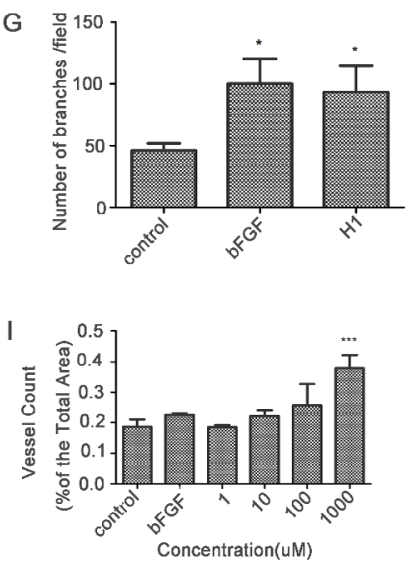

scarification was

calculated using ImageJ software. According to the formula, the repair rate of scarification $\%=$ (the width of the original scratch - the width of the actual scratch) / (the width of the original scratch) x100. (E) Tube formation assay of HUVECs. The cells were seeded on Matrigel-precoated wells and incubated with bFGF $(30 \mathrm{ng} / \mathrm{mL})$ or $\mathrm{H} 1$ peptide $(20 \mu \mathrm{M})$ for $12 \mathrm{~h}$. The number of branches reflecting the ability of tube formation was calculated by ImageJ software. (F) Effect of the $\mathrm{H} 1$ peptide on angiogenesis in chick chorioallantoic membrane assays. Chick embryos were incubated with normal saline, bFGF (100 ng/mL), or H1 peptide of different concentrations for 3 days and then isolated and photographed with a stereomicroscope. Representative images are presented. The blood vessel branch number was quantitated by Image-pro plus v 6.0 software. Experiments were conducted independently in triplicate. The results are expressed as the mean $\pm \mathrm{SD},{ }^{*} \mathrm{P}<0.05 ;{ }^{* * *} \mathrm{P}<0.001$, compared with the control group. 


\section{Cellular Physiology Cell Physiol Biochem 2018;49:1074-1089 and Biochemistry $\begin{aligned} & \text { DOI: 10.1159/000493287 } \\ & \text { Published online: } 6 \text { September, } 2018 \text { www.karger.com/cpb }\end{aligned}$ \\ Zhao et al.: Discovery of H1 Peptide For Skin Wound Healing}

peptide had some binding affinity for FGFR2IIIc. However, whether the H1 peptide bound with high or low affinity was not determined. Thus, ITC was conducted to detect the binding force of the H1 peptide to FGFR2IIIc and other members of the FGFR family. ITC analysis indicated that the $\mathrm{H} 1$ peptide bound to FGFR2IIIc with the highest affinity $\left(\mathrm{K}_{\mathrm{d}} \approx 32.1 \mathrm{nM}\right)$ (Fig. 1F) compared with the other FGFRs (Supplementary Fig. S2A-E).

\section{H1 peptide promotes the proliferation and motility of fibroblasts and vascular endothelial cells}

Fibroblasts and HUVECs play such key roles in the proliferation phase of wound healing that their proliferation may effectively accelerate skin remodeling. In the cell proliferation assay, a CCK8 kit was used to evaluate the effect of the H1 peptide on fibroblasts BALB/c3T3 cells and HUVECs. In addition, bFGF (30 ng/mL) was used as a positive control (Fig. 2A-C). The results suggested that the $\mathrm{H} 1$ peptide $(20 \mu \mathrm{M})$ markedly promoted the proliferation of BALB/c3T3 cells and HUVECs in a dose-dependent manner and enhanced the growth of BALB/c3T3 cells and HUVECs by 2 - and 1.5-fold compared with the blank group, respectively.

In the process of skin wound healing, cell motility is an essential event in addition to cell proliferation. Therefore, we also examined the migration of fibroblasts and the angiogenesis of vascular endothelial cells following treatment with the H1 peptide. A cell scratch assay was conducted, and the results confirmed that, similar to the function of, the H1 peptide enhanced the migration of BALB/c3T3 cells significantly, and its effect was approximately 6 -fold that of the blank group (Fig. 2D, E). The results of the endothelial cell tube formation assay revealed that the H1 peptide clearly promoted tube formation by HUVECs (Fig. 2F, G). In addition, the effect of the $\mathrm{H} 1$ peptide on angiogenesis in vivo was evaluated using a chick embryo chorioallantoic membrane assay (Fig. 2H, I). We observed clearly that both the H1 peptide and bFGF $(100 \mathrm{ng} / \mathrm{mL})$ up-regulated angiogenesis in the chorioallantoic membrane. In addition, the $\mathrm{H} 1$ peptide functioned over over a concentration gradient in which the most significant effect was at a concentration of $1000 \mu \mathrm{M}$.

H1 peptide improves the impairing effect on wound healing in a rat full-thickness wound model in vivo

In addition to the in vitro determinations, we evaluated the effect of the $\mathrm{H} 1$ peptide on accelerating skin wound healing in vivo. We established a rat full-thickness wound model. In this experiment, bFGF $(100 \mu \mathrm{g} / \mathrm{mL})$ was used as a positive control. Compared with the

Fig. 3. $\mathrm{H} 1$ peptide accelerates the healing of full-thickness wounds in rats. (A) Photographs of a representative rat from each group were taken on postoperative days 0,2 , 4, and 6.(B) Representative micrographs of wound histological images (H E staining) at 1 week after treatment. Scale bar $=100 \mu \mathrm{m}$. (C) Representative images of immunohistochemical staining of anti-CK19, anti-PCNA, and anti-CD31 antibodies in each group. Bar
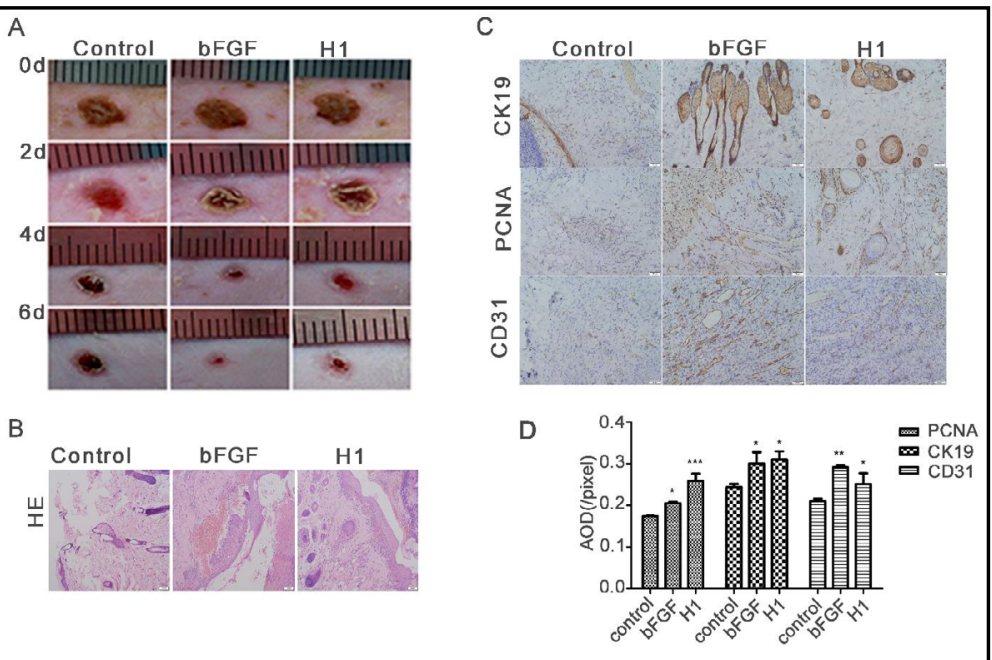
graphs display average optical density (AOD = integrated option density /area) of CK19, PCNA, and CD31 staining by measuring the images with ImageJ software. Scale bar $=50 \mu \mathrm{m}$. The results are expressed as the mean $\pm \mathrm{SD}, * \mathrm{P}<0.05 ;{ }^{* *} \mathrm{P}<0.01$; $* * * \mathrm{P}<0.001$, compared with the control group. 
Fig. 4. H1 peptide activates the PI3KAKT and MAPKERK1/2 signaling pathways and increases the secretion of VEGF. (A) Volcano plot displaying DEGs between the $\mathrm{H} 1$ peptide-treatment and control groups. The y-axis corresponds to the mean expression values of negative log10Pvalues, and the $\mathrm{x}$-axis displays the log2FoldChange values. The red dots represent the up-regulated genes whereas the green dots show the down-regulated genes. $\quad \mathrm{P}<0.05$ was considered to be statistically significant. GO (biological p r o c e s s e s ) enrichment analysis using topGO (version 2.18.0).

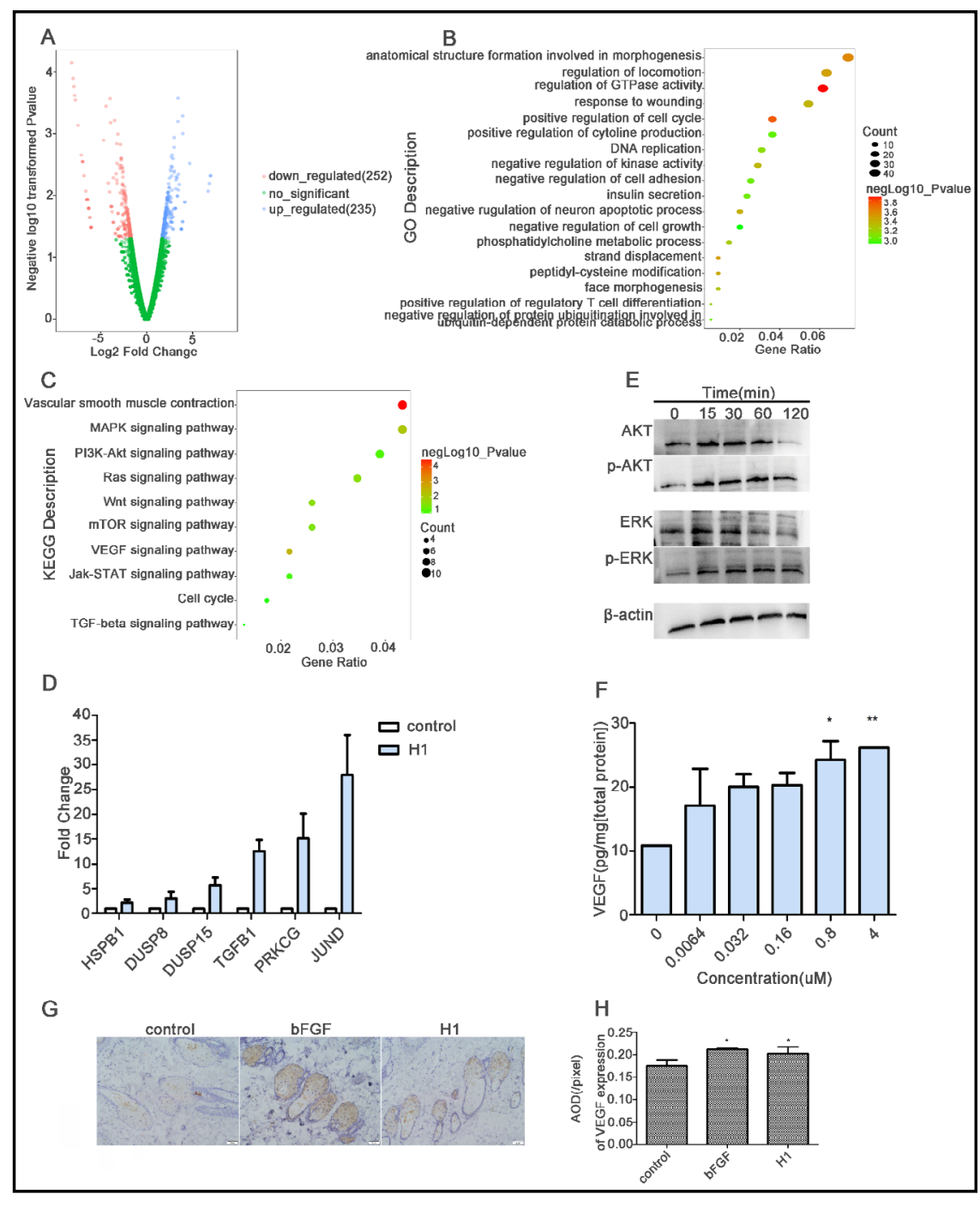

The ordinates represent the enriched GO term; the abscissa denotes gene ratio (the number of genes associated with this biological process / the total number of genes); the size of the dots indicates the number of genes enriched in this biological process, and the color of the dots corresponds to the range of negative $\log 10$ Pvalues. Colors from green to red indicate that negative log10Pvalue are from low to high or that the degree of enrichment is from low to high. (C) KEGG pathway enrichment analysis using KOBAS (version 3.0). The ordinates represent the enriched KEGG pathway. The above data analyses with $\mathrm{P}<0.05$ were considered statistically significant. (D) qPCR analysis validated 6 genes that were differentially expressed between the H1 peptide-treatment group and the control samples by RNA-Seq. TGFB1, PRKCG, JUND, HSPB1, DUSP15, and DUSP8 were evaluated, and 3 independent experiments were performed for qPCR validation. GAPDH was used as a housekeeping control. Fold change was calculated using the $2^{-\Delta \Delta C t}$ method. (E) Effect of the H1 peptide on the AKT and ERK1/2 signaling pathways. In western blot analysis, phospho-AKT (p-Ser473), total AKT, phospho-ERK1/2 (Thr202/Tyr204), and total ERK were detected. HUVECs were treated with the $\mathrm{H} 1$ peptide at different times $(15,30,60$ and $120 \mathrm{~min}) ; \beta$-actin was used as a housekeeping control. (F, G) Effect of the H1 peptide on the secretion of VEGF. (F) HUVECs were incubated with the H1 peptide at different concentrations $(0.0064,0.032,0.16,0.8$, and $4 \mu \mathrm{M}$ ) or vehicle for $24 \mathrm{~h}$, and supernatants of cell cultures were collected. VEGF protein expression was examined by ELISA. (G) Representative images of immunohistochemical staining of VEGF in each group. Bar graphs present average optical density (AOD = integrated option density /area) of VEGF staining by measuring the images. Scale bar $=50 \mu \mathrm{m}$. The results are expressed as the mean $\pm \mathrm{SD}$. ${ }^{*} \mathrm{P}<0.05 ;{ }^{*} \mathrm{P}<0.01$, compared with the control group. 
normal saline treatment group (blank control), we observed that the scabs in the bFGF and the $\mathrm{H} 1$ peptide group sloughed earlier and the new skin tissues were exposed preferentially (Fig. $3 \mathrm{~A})$. The $\mathrm{H} 1$ peptide also showed no side effects on body weight, general health, or the behavior of the rats.

Moreover, the results of $\mathrm{HE}$ staining confirmed that both the $\mathrm{H} 1$ peptide and bFGF led to a more favorable impairing effect on the dermis, epidermis, and hair follicles (Fig. 3B). An immunohistochemistry assay was conducted to further the investigation. PCNA is a marker of cell proliferation, CK19 is a marker of re-epithelialization, and CD31 is a marker of vascular endothelial cells. An increased number of cells was stained for these 3 markers both the $\mathrm{H} 1$ peptide and bFGF groups compared with the untreated group (Fig. 3C, D).
Table 2. Differentially expressed genes between the $\mathrm{H} 1$ peptide-treatment group and control group

\begin{tabular}{|c|c|c|c|}
\hline Gene Symbol & Log2FoldChange & Gene Symbol & Log2FoldChange \\
\hline \multicolumn{4}{|l|}{ Response to wounding } \\
\hline Upregulated genes & & & \\
\hline GP1BB & 3.41 & NT5M & 1.84 \\
\hline RTN4RL2 & 3.40 & TGFB1 & 1.72 \\
\hline PRKCG & 3.01 & HMGA1 & 1.71 \\
\hline CCM2L & 2.67 & PTMS & 1.69 \\
\hline PRTN3 & 2.62 & HRAS & 1.68 \\
\hline ZFPM1 & 2.49 & Downregulate genes & \\
\hline ENTPD2 & 2.40 & FANCM & -2.43 \\
\hline ACHE & 2.35 & RMI1 & -2.23 \\
\hline SH2B2 & 2.13 & BRCA2 & -2.08 \\
\hline APOE & 2.10 & LIG4 & -2.02 \\
\hline HSPB1 & 2.04 & CCNE2 & -1.92 \\
\hline WAS & 2.03 & ATR & -1.86 \\
\hline MYL9 & 1.84 & REV3L & -1.82 \\
\hline ADORA2A & 1.79 & E2F7 & -1.74 \\
\hline RTN4R & 1.74 & DNA2 & -1.67 \\
\hline RHOG & 1.73 & ATRX & -1.62 \\
\hline TGFB1 & 1.72 & Positive regulation of $\mathrm{c}$ & tokine production \\
\hline HRAS & 1.68 & Upregulated genes & \\
\hline MDK & 1.67 & LGALS9 & 3.13 \\
\hline Downregulated genes & & CCM2L & 2.67 \\
\hline PRKAR2A & -2.78 & ZFPM1 & 2.49 \\
\hline FNTB & -2.34 & HSPB1 & 2.04 \\
\hline ITPR1 & -2.30 & ZNF580 & 1.98 \\
\hline HMGCR & -1.92 & СЕВРВ & 1.84 \\
\hline ITGA2 & -1.86 & CLU & 1.76 \\
\hline ADAM17 & -1.83 & TGFB1 & 1.72 \\
\hline DOCK9 & -1.74 & Downregulated genes & \\
\hline PTPN11 & -1.73 & PLCB1 & -3.11 \\
\hline DGKH & -1.73 & IL17RB & -2.94 \\
\hline GJA1 & -1.66 & CYP1B1 & -2.24 \\
\hline DNA replication & & CD46 & -2.03 \\
\hline Upregulated genes & & ARFGEF2 & -1.95 \\
\hline CORT & 3.54 & EIF2AK3 & -1.83 \\
\hline ACHE & 2.35 & ADAM17 & -1.83 \\
\hline
\end{tabular}

H1 peptide induces phosphorylation of the PI3K-AKT and MAPK-ERK1/2 pathways and the secretion of $V E G F$

What is the molecular mechanism underlying the effect of the $\mathrm{H} 1$ peptide in wound healing? To answer this question, we performed the RNA-Seq technique, a large-scale transcriptome sequencing technology, to examine HUVECs treated with the H1 peptide. In this study, DEGs $(\mathrm{P}<0.05)$ were defined as genes that were significantly enriched or depleted in the treatment group compared with the control group. Our results indicated that a total of 487 genes were differentially expressed of which 235 were up-regulated, and 252 were down-regulated in the treatment group (Fig. 4A). Table 2 lists some statistically significant DEGs.

On the basis of the RNA-Seq results, GO annotation (biological process) analysis indicated that the biological process of "response to wound" was remarkably enriched (Fig. 4B). In addition, KEGG pathway analysis revealed that some pathways were significantly enriched, such as the MAPK, PI3K-AKT and VEGF signaling pathways (Fig. 4C).

To ensure the credibility of the RNA-Seq results, 6 up-regulated genes were randomly selected to be confirmed by qPCR assay. The results were consistent, verifying that the RNASeq data were convincing (Fig. 4D).

It is well documented that the PI3K-AKT and MAPK signaling pathways are critical in regulating cell proliferation [32-35]. In this study, KEGG analysis provided similar results. A western blot assay also presented corresponding results that the phosphorylation levels of AKT and ERK were significantly increased in the treatment group (Fig. 4E), definitively indicating that the $\mathrm{H} 1$ peptide activated the AKT and ERK signaling pathways.

Many cytokines, such as transforming growth factor (TGF)- $\beta$, interleukin (IL)-6, and VEGF, are important in wound healing $[7,8,36]$. VEGF, in particular, is a key regulator of physiological angiogenesis during skeletal growth, embryogenesis and reproductive functions [37, 38], and wound healing [39-41]. According to KEGG analysis, the VEGF signaling pathway was 


\section{Cellular Physiology Cell Physiol Biochem 2018;49:1074-1089 and Biochemistry DOI: 10.1159/000493287 20102018 The Author(s). Published by S. Karger AG, Basel

also markedly enriched. An ELISA indicated that HUVECs treated with the $\mathrm{H} 1$ peptide led to an increase of VEGF in the cell culture supernatant in a dose-dependent manner (Fig. 4F). In addition, immunohistochemistry indicated that the expression of VEGF was greatly increased in both the $\mathrm{H} 1$ peptide and bFGF groups (Fig. 4G, $\mathrm{H})$.

Collectively, these results suggested that the $\mathrm{H} 1$ peptide had a gain-of-function to improve skin wound healing by activating the PI3K-AKT and MAPKERK1/2 signaling pathways and simultaneously inducing the expression of VEGF.

Molecular docking analysis of $\mathrm{H} 1$ peptide binding with FGFR2IIIC

To explore further the structural biology mechanism of the $\mathrm{H} 1$ peptide, LeDock software 42 was used to simulate the binding model of the $\mathrm{H} 1$ peptide and extracellular segment of FGFR2IIIc. The crystal structure of the FGFR2IIIc extracellular domain was derived from the Protein Data Bank (PDB code: 1EV2). Docking scores were calculated by the binding free energies. In the process of docking, the entire $F$ chain of FGFR2IIIc was used as our docking area. The $\mathrm{F}$ chain contains the D2 and D3 regions of the extracellular domain of FGFR2IIIc, which is the critical region for FGFR2IIIc binding to its ligand. The software was set to sort the first 20 conformations according to the scoring function. Docking results indicated that the 20 binding conformations were all concentrated in the D2-D3 linker region (Supplementary Fig. S3). According to the above preliminary docking results, the D2D3 linker region was selected as our further docking area in which LeDock was rerun for a conformational search. The optimal conformation was obtained as our analysis object.

The docking results indicated that the $\mathrm{H} 1$ peptide was located in the active pocket of FGFR2IIIc, which was comprised of Val249, Glu250, Arg251, Ser252, Lys279, Tyr281, Ser282, Asp283, Gln285, Pro286, and Asp321, and formed a wide range of noncovalent interactions

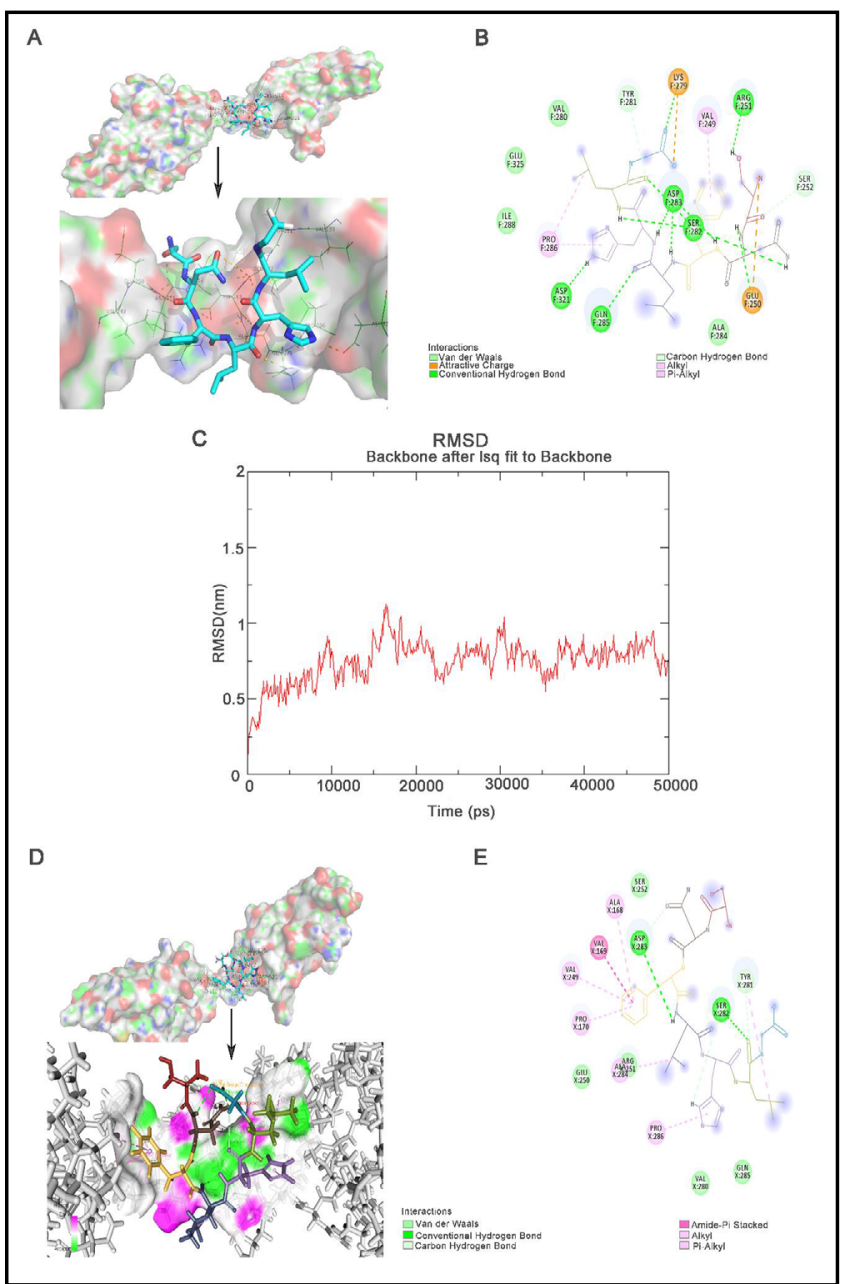

Fig. 5. Structural biological analysis of the binding mode of the H1 peptide with FGFR2IIIc. (A, B) Molecular docking analysis of the $\mathrm{H} 1$ peptide binding with FGFR2IIIc. (A) Three-dimensional image of the molecular docking result visualized by PyMOL. (B) Two-dimensional image of the molecular docking result visualized by Discovery studio 4.5 visualizer. (C, E) Molecular dynamics simulation analysis of the H1-FGFR2IIIc complex system. (C) The RMSD value of the H1-FGFR2IIIc complex by molecular dynamics simulation of $50 \mathrm{~ns}$. (D) Three-dimensional image of the complex system in molecular dynamics simulation of 14 ns visualized by Discovery studio 4.5 visualizer. (E) Twodimensional image of the complex by molecular dynamics simulation of $14 \mathrm{~ns}$. Arrow represents local magnified regions. Dashed lines represent non- covalent bonds between amino acids. 


\section{Cellular Physiology Cell Physiol Biochem 2018;49:1074-1089 and Biochemistry Published online: 6 September, 2018 www.karger.com/cpb \\ Zhao et al.: Discovery of H1 Peptide For Skin Wound Healing}

with them (Fig. 5A, B). The $\mathrm{H} 1$ peptide was folded at the center of the Leu4 residue. Asp283 in FGFR2IIIc was located in the geometric center of the H1 peptide binding pocket, forming hydrogen bonding interactions with His5, Leu4, and Phe3 of the H1 peptide. Among the $\mathrm{H} 1$ peptide sequence, the benzene ring of Phe3 and the imidazolyl group of His5 formed pi bonds with Val249 and Pro286 of FGFR2IIIc, respectively; the amide groups of Asn2 and an amino group of Leu6 formed a hydrogen bond with Asp283 of FGFR2IIIc, respectively; Leu4 and Ser1 were structurally located on both sides of the D2-D3 linker, both of which were folded toward the inside of the active pocket to maintain the stability of the binding of the $\mathrm{H} 1$ peptide to the active pouch. Recorded X-ray diffraction data have indicated that the sites of bFGF interactions with FGFR2IIIc are located in the D2-D3 linker region, in which Leu166, Ala168, Pro170, Val249, Arg251, Asp283, Val317, Asn318, and Asp321 are the core amino acids of these interactions 43. Compared with the binding mode of bFGF and FGFR2IIIc, the $\mathrm{H} 1$ peptide had strong similarity and exhibited perfect geometric matching in the active cavity of the FGFR2IIIc receptor.

Subsequently, we conducted molecular dynamics simulations of 50 ns to verify the stability of the H1-FGFR2IIIc complex in ionic solvents. The root mean square deviation (RMSD) parameter is an important index to measure whether a system is stable [44, 45]. The results indicated that the RMSD value of the H1-FGFR2IIIc complex began to increase sharply at $14 \mathrm{~ns}$, reached its peak at $17 \mathrm{~ns}$, and then gradually stabilized (Fig. 5C). At $14 \mathrm{ns,}$ Ser1 and Leu4 continued to maintain the geometric match of the H1 peptide with the D2D3 linker associated with the initial conformation. However, some changes also remained. In addition to the formation of the pi bond with Val249, the benzene ring of Phe3 increased the formation of the pi bond with Ala168, Val169 and Pro170 in the active pocket, and the D2-D3 linker region of FGFR2IIIc was folded inward at the center of the H1 peptide, leading to a deeper FGFR2IIIc activity pocket (Fig. 5D, E). Simultaneously, the folding was basically restored after $23 \mathrm{~ns}$, and the folding time was consistent with the time of RMSD change.

Collectively, these results suggested that the $\mathrm{H} 1$ peptide had a dynamic effect on FGFR2IIIc and that the residues of the $\mathrm{H} 1$ peptide interacting with FGFR2IIIc basically included the core residues of bFGF and FGFR2IIIc binding.

\section{Discussion}

In this study, using phage display, we identified a novel small peptide, $\mathrm{H} 1$, targeting FGFR2IIIc with high affinity. As the H1 peptide demonstrated potentially facilitative effects on skin wound healing, we also explored its mechanism in vitro, in vivo, and at the structural biology level. In brief, the results indicated that the H1 peptide promoted the proliferation and motility of fibroblasts and vascular endothelial cells (Fig. 2). It also promoted angiogenesis in the chick chorioallantoic membrane and accelerated wound healing in a rat full-thickness wound model in vitro (Fig. 3). The $\mathrm{H} 1$ peptide activated the PI3K-AKT and MAPK-ERK1/2 signaling pathways and simultaneously induced the secretion of VEGF (Fig. 4). It also exhibited the highest affinity with FGFR2IIIc $\left(\mathrm{K}_{d} \approx 32.1 \mathrm{nM}\right)$ compared with other FGFRs (Figs. 1F and S2), and its binding model was further revealed using molecular docking calculations and molecular dynamics simulations (Fig. 5).

Using a phage-displayed peptide library, 4 small peptides were obtained in this study, $\mathrm{H} 1, \mathrm{H} 2, \mathrm{H} 3$, and H4. Although all 4 peptides showed high affinities with FGFR2IIIc, only the H1 peptide had the desired bioactivity (Fig. 1E). Referring to the structural biology results (Fig. 5), we assumed that the H2, H3, and H4 peptides may have different binding sites with FGFR2IIIc that led to the distinct spatial structural changes in FGFR2IIIc. Moreover, the binding mode of the H1 peptide to FGFR2IIIc was highly similar to that of bFGF and FGFR2IIIc, indicating that the H1 peptide could cause FGFR2IIIc to undergo conformational changes similar to those that occur in the presence of bFGF (Fig. 5A, B). In addition, it is welldocumented that bFGF activates the intracellular PI3K-AKT and MAPK signaling pathways $[46,47]$. Similarly, the H1 peptide could induce the phosphorylation of the PI3K-AKT and 
MAPK-ERK1/2 pathways in vitro (Fig. 4). It suggested that the H1 peptide must execute the considerable biological function of bFGF.

Our institute developed recombinant bFGF for the treatment of for burns, scalds, and chronic ulcers 20 years ago. However, because recombinant bFGF degrades easily, it requires strict storage and transport conditions. In clinical applications, it also leads to the low accumulation of bFGF at on therapeutic sites, an undesired effect. Compared with recombinant proteins, small peptides have many advantages such as small molecular weight and low production cost. As the $\mathrm{H} 1$ peptide has such a strong effect on cell proliferation, we believe that it could be a potential candidate drug to replace bFGF for skin repair. Of course, the application of the $\mathrm{H} 1$ peptide should be strictly evaluated in cases of abnormal cell proliferation, such as scars, tumor, and fibrosis.

In this study, we used computational biology software to examine the binding patterns of the H1 peptide to FGFR2IIIc (Fig. 5A, B). The difficulty is that the H1 peptide has great flexibility. To solve such a problem, simulated annealing and genetic algorithms were combined to optimize semi-flexible docking. Meanwhile, we monitored the process of forming the binding pattern by long-time molecular dynamics simulation (Fig. 5C). In the course of molecular dynamics simulation, we used the interval sampling method to obtain non-covalent bond formation of the H1-FGFR2IIIc complex. This may improve the accuracy of molecular docking and further define the stability of the H1-FGFR2IIIc complex. The approach we employed may prompt other investigators to simulate peptide-protein complexes in the future.

\section{Conclusion}

This study demonstrated that the $\mathrm{H} 1$ peptide played a biological role by activating FGFR2IIIc. Compared with the natural ligand bFGF, no significant functional differences were observed in this study. However, because they are so different in sequence, the H1 peptide may have unknown functions or characteristics. In addition, the members of the receptor tyrosine kinase family have high homology [48]. Thus, the H1 peptide may bind to other receptor tyrosine kinase proteins and affect the relevant signaling pathways. To address these issues, the $\mathrm{H} 1$ peptide must be explored deeply in the future.

In brief, we discovered a novel small peptide for the treatment of skin wounds which may be developed as a prospective candidate drug.

\section{Acknowledgements}

This study was supported by a grant from the Science and Technology Program of Guangdong Province (No. 2016A020217012), a grant from the Science and Technology Program of Guangzhou (No. 2016201604030039), and a grant from the Chinese National Natural Science Foundation (No. 81473131).

\section{Disclosure Statement}

The authors declare no conflict of interests.

\section{References}

\footnotetext{
1 Nguyen DT, Orgill D, Murphy GF: The pathophysiologic basis for wound healing and cutaneous regeneration. Biomaterials for treating skin loss 2009; pp25-57.
} 


\section{Cellular Physiology Cell Physiol Biochem 2018;49:1074-1089 and Biochemistry DOI: 10.1159/000493287 202018 The Author(s). Published by S. Karger AG, Basel

2 Rieger S, Zhao H, Martin P, Abe K, Lisse TS: The role of nuclear hormone receptors in cutaneous wound repair. Cell Biochem Funct 2015;33:1-13.

3 Stadelmann WK, Digenis AG, Tobin, GR: Physiology and healing dynamics of chronic cutaneous wounds. Am J Surg 1998;176:26-38.

4 Velnar T, Bailey T, Smrkolj V: The wound healing process: an overview of the cellular and molecular mechanisms. J Int Med Res 2009;37:1528-1542.

5 Martin P: Wound healing-aiming for perfect skin regeneration. Science 1997;276:75-81.

6 Aschermann I, Noor S, Venturelli S, Sinnberg T, Mnich CD, Busch C: Extracorporal shock waves activate migration, proliferation and inflammatory pathways in fibroblasts and keratinocytes, and improve wound healing in an open-label, single-arm study in patients with therapy-refractory chronic leg ulcers. Cell Physiol Biochem 2017;41:890-906.

7 Werner S, Grose R: Regulation of wound healing by growth factors and cytokines. Physiol Rev 2003;83:835870 .

8 Barrientos S, Stojadinovic 0, Golinko MS, Brem H, Tomic-Canic M: Growth factors and cytokines in wound healing. Wound Repair Regen 2008;16:585-601.

-9 Bai Y, Xu R, Zhang X, Zhang X, Hu X, Li Y, Li H, Liu M, Huang Z, Yan R, He W, Luo G, Wu J: Differential role of rapamycin in epidermis-induced IL-15-IGF-1 secretion via activation of Akt/mTORC2. Cell Physiol Biochem 2017;42:1755-1768.

10 Barrientos S, Brem H, Stojadinovic 0, Tomic-Canic M: Clinical application of growth factors and cytokines in wound healing. Wound Repair Regen 2014;22:569-578.

11 Rinsch C, Quinodoz P, Pittet B, Alizadeh N, Baetens D, Montandon D, Aebischer P, Pepper MS: Delivery of FGF-2 but not VEGF by encapsulated genetically engineered myoblasts improves survival and vascularization in a model of acute skin flap ischemia. Gene Ther 2001;8:523-533.

12 Shi H, Xu X, Zhang B, Xu J, Pan Z, Gong A, Zhang X, Li R, Sun Y, Yan Y, Mao F, Qian H, Xu W: 3, 3'-Diindolylmethane stimulates exosomal Wnt11 autocrine signaling in human umbilical cord mesenchymal stem cells to enhance wound healing. Theranostics 2017;7:1674-1688.

13 Coutts JC, Gallagher JT: Receptors for fibroblast growth factors. Immunol Cell Biol 1995;73:584-589.

$\checkmark 14$ Powers CJ, Mcleskey SW, Wellstein A: Fibroblast growth factors, their receptors and signaling. Endocr Relat Cancer 2000;7:165-197.

15 Stauber DJ, DiGabriele AD, Hendrickson WA: Structural interactions of fibroblast growth factor receptor with its ligands. Proc Natl Acad Sci U S A 2000;97:49-54.

16 Eswarakumar VP, Monsonego-Ornan E, Pines M, Antonopoulou I, Morriss-Kay GM, Lonai P: The IIIc alternative of Fgfr2 is a positive regulator of bone formation. Development. 2002;129:3783-3793.

17 Katoh M: FGFR2 abnormalities underlie a spectrum of bone, skin, and cancer pathologies. J Invest Dermatol 2009;129:1861-1867.

18 Zhang J, Upadhya D, Lu L, Reneker LW: Fibroblast growth factor receptor 2 (FGFR2) is required for corneal epithelial cell proliferation and differentiation during embryonic development. PLoS One 2015;10:e0117089.

19 Goetz R, Mohammadi M: Exploring mechanisms of FGF signalling through the lens of structural biology. Nat Rev Mol Cell Biol 2013;14:166-180.

-20 Helsten T, Schwaederle M, Kurzrock R: Fibroblast growth factor receptor signaling in hereditary and neoplastic disease: biologic and clinical implications. Cancer Metastasis Rev 2015;34:479-496.

21 Katoh M: Therapeutics targeting FGF signaling network in human diseases. Trends Pharmacol Sci 2016;37:1081-1096.

22 Zhao H, Yang T, Madakashira BP, Thiels CA, Bechtle CA, Garcia CM, Zhang H, Yu K, Ornitz DM, Beebe DC, Robinson ML: Fibroblast growth factor receptor signaling is essential for lens fiber cell differentiation. Dev Biol 2008;318:276-288.

23 Akita S, Akino K, Hirano A: Basic fibroblast growth factor in scarless wound healing. Adv Wound Care (New Rochelle) 2013;2:44-49.

24 Peng Y, Li P, Zhao ZA, Chen L, Zhao XG, Chen X, Zhao Y, Xiong RP, Ning YL, Yang N, Ye J, Zhou YG: Comparative evaluation of the wound-healing potency of recombinant bFGF and ski gene therapy in rats. Growth Factors 2016;34:119-127.

25 Robinson MD, McCarthy DJ, Smyth GK: edgeR: a Bioconductor package for differential expression analysis of digital gene expression data. Bioinformatics 2010;26:139-140. 


\section{Cellular Physiology Cell Physiol Biochem 2018;49:1074-1089 \begin{tabular}{l|l|l|l} 
DOI: 10.1159/000493287 & (c) 2018 The Author(s). Published by S. Karger AG, Basel
\end{tabular} and Biochemistry Published online: 6 September, 2018 www.karger.com/cpb}

Zhao et al.: Discovery of H1 Peptide For Skin Wound Healing

-26 Liu MM, Xing YM, Zhang DW, Guo SX: Transcriptome analysis of genes involved in defence response in polyporus umbellatus with armillaria mellea infection. Sci Rep 2015;5:16075.

27 Xie C, Mao X, Huang J, Ding Y, Wu J, Dong S, Kong L, Gao G, Li CY, Wei L: KOBAS 2.0: a web server for annotation and identification of enriched pathways and diseases. Nucleic Acids Res 2011;39:W316-322.

28 Livak KJ, Schmittgen TD: Analysis of relative gene expression data using real-time quantitative PCR and the 2(-Delta Delta C(T)) method. Methods 2001;25:402-408.

-29 Shoiohet BK: Virtual screening of chemical libraries. Nature 2004;432:862-865.

-30 Yuriev E, Ramsland PA: Latest developments in molecular docking: 2010-2011 in review. J Mol Recognit 2013;26:215-239.

-31 Yuriev E, Holien J, Ramsland PA: Improvements, trends, and new ideas in molecular docking: 2012-2013 in review. J Mol Recognit 2015;28:581-604.

-32 Chang F, Lee JT, Navolanic PM, Steelman LS, Shelton JG, Blalock WL, Franklin RA, McCubrey JA: Involvement of PI3K/Akt pathway in cell cycle progression, apoptosis, and neoplastic transformation: a target for cancer chemotherapy. Leukemia 2003;17:590-603.

33 Zhou C, Qiu L, Sun Y, Healey S, Wanebo H, Kouttab N, Di W, Yan B, Wan Y: Inhibition of EGFR/PI3K/AKT cell survival pathway promotes TSA's effect on cell death and migration in human ovarian cancer cells. Int J Oncol 2006;29:269-278.

34 Gedaly R, Angulo P, Hundley J, Daily MF, Chen C, Koch A, Evers BM: PI-103 and sorafenib inhibit hepatocellular carcinoma cell proliferation by blocking Ras/Raf/MAPK and PI3K/AKT/mTOR pathways. Anticancer Res 2010;30:4951-4958.

-35 Zhou T, Yang Z, Chen Y, Chen Y, Huang Z, You B, Peng Y, Chen J: Estrogen accelerates cutaneous wound healing by promoting proliferation of epidermal keratinocytes via Erk/Akt signaling pathway. Cell Physiol Biochem 2016;38:959-968.

-36 Chen J, Chen Y, Chen Y, Yang Z, You B, Ruan YC, Peng Y: Epidermal CFTR suppresses MAPK/NF-kB to promote cutaneous wound healing. Cell Physiol Biochem 2016;39:2262-2274. Ferrara N, Gerber HP, LeCouter J: The biology of VEGF and its receptors. Nat Med 2003;9:669-676.

-38 Cao R, Eriksson A, Kubo H, Alitalo K, Cao Y, Thyberg J: Comparative evaluation of FGF-2-, VEGF-A-, and VEGF-C-induced angiogenesis, lymphangiogenesis, vascular fenestrations, and permeability. Circ Res 2004;94:664-670.

39 Frank S1 HG, Breier G, Longaker MT, Greenhalgh DG, Werner S: Regulation of vascular endothelial growth factor expression in cultured keratinocytes. Implications for normal and impaired wound healing. J Biol Chem 1995;270:12607-12613.

40 Ko J, Ross J, Awad H, Hurwitz H, Klitzman B: The effects of ZD6474, an inhibitor of VEGF signaling, on cutaneous wound healing in mice. J Surg Res 2005;129:251-259.

41 Santos SC, Miguel C, Domingues I, Calado A, Zhu Z, Wu Y, Dias S: VEGF and VEGFR-2 (KDR) internalization is required for endothelial recovery during wound healing. Exp Cell Res 2007;313:1561-1574.

42 Wang Z, Sun H, Yao X, Li D, Xu L, Li Y, Tian S, Hou T: Comprehensive evaluation of ten docking programs on a diverse set of protein-ligand complexes: the prediction accuracy of sampling power and scoring power. Phys Chem Chem Phys 2016;18:12964-12975.

-43 Plotnikov AN, Hubbard SR, Schlessinger J, Mohammadi M: Crystal structures of two FGF-FGFR complexes reveal the determinants of ligand-receptor specificity. Cell 2000;101:413-424.

44 Plattner N, Doerr S, De Fabritiis G, Noe F: Complete protein-protein association kinetics in atomic detail revealed by molecular dynamics simulations and Markov modelling. Nat Chem 2017;9:1005-1011.

45 Perilla JR, Schulten K: Physical properties of the HIV-1 capsid from all-atom molecular dynamics simulations. Nat Commun 2017;8:15959.

46 Shi YH, Wang YX, Bingle L, Gong LH, Heng WJ, Li Y, Fang WG: In vitro study of HIF-1 activation and VEGF release by bFGF in the T47D breast cancer cell line under normoxic conditions: involvement of PI-3K/Akt and MEK1/ERK pathways. J Pathol 2005;205:530-536.

47 Shi YH, Bingle L, Gong LH, Wang YX, Corke KP, Fang WG: Basic FGF augments hypoxia induced HIF-1-alpha expression and VEGF release in T47D breast cancer cells. Pathology 2007;39:396-400.

-48 Hubbard SR: Structural analysis of receptor tyrosine kinases. Prog Biophys Mol Biol 1999;71:343-358. 